\title{
Control of Diabetes through Phytomedicine-A Case Report
}

\author{
Prof.em.Dr. Ather Amina ${ }^{1 *}$, Umme Umarah Nusaibah ${ }^{2}$ \\ ${ }^{1}$ Research Head, Department of RIDM (Research, Innovation, Development and Marketing), System 4 Technologies, \\ Oldenburg, Germany \\ ${ }^{2}$ Student, Department of RIDM (Research, Innovation Development and Marketing), System 4 Technologies, Oldenburg, \\ Germany
}

*Address for Correspondence: Prof.em.Dr. Ather Amina, Research Head, Department of RIDM (Research, Innovation, Marketing and Development), System 4 Technologies, Oldenburg, Germany

E-mail: a.ather@system4-technologies.com

Received: 09 Dec 2018/ Revised: 16 Mar 2019/ Accepted: 15 Jun 2019

\begin{abstract}
Background: The prevalence of diabetes is growing worldwide. The primary symptom of diabetes mellitus is elevated blood sugar. This is usually treated with lifestyle intervention and drugs.

Methods: A 60-year-old female was diagnosed with diabetes with a random sugar level of $350 \mathrm{mg} / \mathrm{dL}^{-1}$ six months back. The doctor prescribed Tablet Metformin $(\mathrm{HCl}) 500 \mathrm{mg}$ once a day to a patient and advised blood sugar test after the end of 15 days medication followed by blood sugar test to continue with above medication for till the life. This study was being conducted at the beginning of March month to May month, in the Department of RIDM (Research, Innovation, Development and Marketing) system 4 technologies, Oldenburg, Germany.

Results: The above treatment was not found satisfactory to the patient as she was having associated problem with this medication like stomach ache and nausea. However, after starting with Unani treatment followed by meditation and morning walk, the patient started to recover and feel satisfied with this treatment within a one month.

Conclusion: It was suggested that Royal jelly ameliorate cyclophosphamide-induced hematological alterations, thus it might be used as a dietary protective natural remedy during the chemotherapy.
\end{abstract}

Key-words: Diabetes, Heterogeneous, Life-threatening diseases, Metformin, Phytomedicine

\section{INTRODUCTION}

Diabetes mellitus (DM) is one of the most leading chronic, heterogeneous and life-threatening diseases and today it has spread to every region of the globe. The prevalence of DM will be $5.4 \%$ by the year 2025 , with the global diabetic population reaching to 300 million ${ }^{[1]}$. In a diabetic patient, frequent urination, increased hunger and thirst, decreased bodyweight, blurred vision, itching and tiredness are common symptoms ${ }^{[2]}$.

Nowadays, there are a lot of options available to treat type 2 diabetes with the help of various antihyperglycemic medications, such as insulin, sulfonylurea as and Metformin.

\section{How to cite this article}

Amina A, Nusaibah UU. Control of Diabetes through Phytomedicine-A Case Report. SSR Inst. Int. J. Life Sci., 2019; 5(4): 2361-2364.

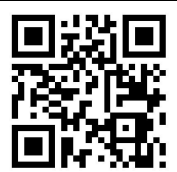

Access this article online https://iijls.com/
Although, these drugs have ability to reduce blood sugar level but the recommendation of one class of antihyperglycemic agents or a certain combination to treat complications of diabetes is still difficult ${ }^{[4]}$. On the other hand Unani medicine has the ability to treat diabetes in various ways like diet planning exercise; as good lifestyle, healthy food and exercise will always remain effective in the management of diabetes. Moreover, Unani herbs like Azadirachta indica, Momordica charantia, and Murraya koenigii. Here in, a case study is discussed based on the treatment diabetes with the help of both allopathic and ayurvedic medicines in which phytomedicine treatment were found more effective.

CASE REPORT- A 60-year-old Indian female was coincidentally diagnosed with diabetes around 6 months back with a random blood sugar level of $325 \mathrm{mg} / \mathrm{dL}$ as measured by a blood glucose monitoring device (ONE TOUCH select simple, life'scan Europe division cilag $\mathrm{GmbH}$ International Switzerland). Surprisingly she was 
not having any symptoms of diabetes. Her blood sugar level was randomly checked at home i.e. $350 \mathrm{mg} / \mathrm{dL}$. In the next day observation, the fasting blood glucose level was found to $165 \mathrm{mg} / \mathrm{dL}$ and post prandial (PP) glucose level was found to $190 \mathrm{mg} / \mathrm{dL}$. After this shocking revelation she consulted to a general physician. Before starting the treatment the doctor asked her about her previous medical history and he found no history of hypothyroidism, kidney diseases, and hypertension. In addition, her father-in-law was a type 2 diabetes patient for the past 10 years as per doctors measurements her weight was $58 \mathrm{~kg}$, height was 152 impulse rate $92 \mathrm{bpm}$ and blood pressure was $130 / 80 \mathrm{mmHg}$. The doctor prescribed Metformin $\mathrm{HCl}(500 \mathrm{mg}$ ) once a day for 15days and advised some blood tests after 15-day medication. The blood tests advised by the doctor for sugar (F/PP). The doctor was also advised to stop rich sugar foods like rice sweets etc immediate after starting the treatment. She complained of nausea and could not intake proper food. She consulted the doctor again about this problem but doctor told her that this is normal and she has to continue her treatment. She completed her 15 days treatment with very difficult time and went to pathology lab for blood tests as advised by the doctor. The pathology report of the woman is given in Table 1.

After studying the above report, the doctor advised to continue with Metformin $\mathrm{HCl}(500 \mathrm{mg}$ ) once a day for next 30 days. During this treatment, the women continued having the problem of nausea, indigestion and acidity. Thereafter, doctor advised to continue this treatment for one more month. The patient started to worry about the association problems like acidity nausea etc, started to search for another doctor for her treatment.

Table 1: Laboratory data of the patient

\begin{tabular}{ccc}
\hline Examination & Observed value & $\begin{array}{c}\text { Reference } \\
\text { range }\end{array}$ \\
\hline $\begin{array}{c}\text { Fasting Blood } \\
\text { glucose }\end{array}$ & $105 \mathrm{mg} / \mathrm{dL}$ & $70-100 \mathrm{mg} / \mathrm{dL}$ \\
*Post Prandial & $173 \mathrm{mg} / \mathrm{dL}$ & $70-150 \mathrm{mg} / \mathrm{dL}$ \\
Blood glucose & & \\
\hline
\end{tabular}

\section{*After $\mathbf{2} \mathrm{h}$ of meal}

Finally, she consulted a Unani researcher cum doctor and shared her whole medical history with her. After examining all the reports and earlier prescription, the doctor advise first to stop the medication then detox therapy, which is called Munzij (concoction) and Mushil (purgation) which included as regimental therapies ${ }^{[5]}$. In Unani medicine, for a week in which patient has to follow strictly eat only raw vegetables like cucumber, sprouted beans, soaked chana (Bengal gram), soaked peanuts for 7 days along with tamarind water in early morning she advised the patient for blood sugar level after 7 day's. Doctor advised to do dry cupping ${ }^{[6]}$ on particular points that removed the toxins from the body of the patient.

The patient followed doctor's advice and after 7 days, she went to the pathology lab for blood sugar level test. Her Fasting blood glucose level was found to $110 \mathrm{mg} / \mathrm{dL}$ and post-prandial $136 \mathrm{mg} / \mathrm{dL}$. The laboratory report has given in Table 2.

Table 2: Laboratory data of the patient with reference values for the tests

\begin{tabular}{ccc}
\hline Examination & $\begin{array}{c}\text { Observed } \\
\text { value }\end{array}$ & Reference range \\
\hline $\begin{array}{c}\text { Fasting Blood } \\
\text { glucose } \\
\begin{array}{c}\text { Post Prandial } \\
\text { Blood glucose }\end{array}\end{array}$ & 110 & $70-100 \mathrm{mg} / \mathrm{dL}$ \\
\hline
\end{tabular}

Patient was mesmerized seeing the result and she wanted to continue with further treatment. The doctor prescribed her 3 month course to treat diabetes in which she advised spleen detox (Wheatgrass juice 1 glass every day empty stomach), colon cleansing ( 2 drops of almond oil with 1 cup of warm water every night before sleeping. Mint and warm water in morning empty stomach before wheatgrass juice). Anti-inflammatory and antioxidant diet (Ginger in the diet, fish Salmon smoked salmon with wheat bread for breakfast salmon with rosemary for dinner that food richer in beta cartoon like carrot and pumpkin) can increase immunity, regularly herb Tinospora cordifolia balli in 500 mg/day called Amrutha Balli Indian language.

Monday Anti-inflammatory: Zingiber officinale Rosc. Ginger $5 \mathrm{mg}$ once in a day. On Tuesday, Liminoids and polyphenolic flavonoid Neem (Azadirachta indica) $5 \mathrm{mg}$ was taken once in a day. Wednesday triterpenoids and saponins Centella asiatica (Brahmi): 5 gm once in a day, Thursday, Steroidal Lactones Withania somnifera 
(Ashwagandha): $5 \mathrm{gm}$ once in a day. On Friday, Momordica charantia karela $5 \mathrm{gm}$ had taken once in a day. Saturday Stomachic and Nicotinic acid: Murayya koenigii (curry leaf) $5 \mathrm{mg}$ once in a day. Sunday Anti-inflammatory and blood thinner Hibiscus Hibiscus rosa sinensis $5 \mathrm{gm}$ along with vitamin D3 (taken sunlight in early morning), 30 minute meditation for helping in the oxidation of blood, early morning walk, breathing exercise daily. As per doctor's advice, she was continuing the exercises and morning walk; meanwhile the patient felt nausea and could not taken improper food then she can take proper food and the nausea was stopped. After that, she was living freely managing diet and stress.

\section{DISCUSSION}

There were so many reasons behind diabetes, in which genetic factor was considered to be the most possible cause. Besides, stress, unhealthy lifestyle and imbalanced diet are also the major causes of diabetes ${ }^{[7]}$. In the present case stress, unhealthy lifestyle, lack of exercise might be the possible cause of diabetes. Higher levels of stress can cause blood glucose to rise, which was supported by various evidence-based studies. High stress in life may affect diabetes in terms of both its onset and its exacerbation through physiological mechanisms and via behavior ${ }^{[8]}$. In present case, the stress may be the major cause of type 2 diabetes in woman as she was stressful due to over workload of her house hold work apart from above causes. The menopause is one of the factor, after menopause estrogen level becomes low that tend to adversely affect body fat distribution and accumulation, appetite, insulin secretion, glucose homeostasis, increases the risk of developing type 2 diabetes in women ${ }^{[9]}$.

Treatment of the diabetes was challenging, although its management is possible with the help of medication and improved lifestyle ${ }^{[10]}$. The allopathic drugs i.e. Metformin used to manage type 2 diabetes but in the present case, it found unsatisfactory to the patient as woman could not get relieve nausea etc symptoms having associated with this medication. Hence, there was an urgent need for alternative treatment to control blood sugar level and to avoid possible complications due to type 2 diabetes.

\section{CONCLUSIONS}

In this study, we were concluded that the use of phytomedicine or Unani herbs i.e. tinospora cordifolia balliin, Azadirachta indica, Centella asiatica, Zingiber officinale Rosc., Withania somnifera, Momordica charantia, Murayya koenigii, Hibiscus rosa-sinensis to found effective to control blood sugar level, increasing the immunity power and reduces the possible complications of diabetes.

This alternative treatment can be considered as the most effective treatment because of its ability to control blood sugar level and also have fewer side effects as compared to that of allopathic medicines.

\section{ACKNOWLEDGMENTS}

All Authors were Thankful to the Department of RIDM for providing all necessary facilities.

\section{CONTRIBUTION OF AUTHORS}

Research concept- Prof.em.Dr.Ather A

Research design- Prof.em.Dr.Ather $A$

Supervision- Prof.em.Dr.Ather A

Materials- Dr. Umme Umarah Nusaibah

Data collection- Dr. Umme Umarah Nusaibah

Data analysis and Interpretation- Prof.em.Dr.Ather A

Literature search- Prof.em.Dr.Ather A, Dr. Umme Umarah Nusaibah

Writing article- Dr. Umme Umarah Nusaibah

Critical review- Prof.em.Dr.Ather A

Article editing-Prof.em.Dr.Ather A

Final approval- Prof.em.Dr.Ather A

\section{REFERENCES}

[1] Semwal DK, Rawat U, Semwal R, Singh R, Singh GJP. Anti-hyperglycemic effect of 11-hydroxypalmatine, a palmatine derivative from Stephania glabra tubers. J. Asian Nat. Prod. Res., 2010; 12: 99-105.

[2] Bastaki S. Diabetes mellitus and its treatment. Int. J. Diabetes Metab., 2005; 13: 111-134.

[3] Ripsin CM, Kang H, Urban RJ. Management of blood glucose in type 2 Diabetes mellitus. Am. Family Physician, 2009; 79: 29-36.

[4] Nathan DM, Buse JB, Davidson MB, Ferrannini E, Holman RR, et al. Medical management of hyperglycemia in type 2 diabetes: a consensus algorithm for the initiation and adjustment of therapy: a consensus statement of the American Diabetes Association and the European Association for the Study of Diabetes. Diabetes Care, 2009; 32(1): 193-203. doi: 10.2337/dc08-9025. 
[5] Firdaus S, Sultana N. Regimenal therapy a drugless regimen for well being of a person in USM and its important place in the Mainstream Treatment of USM. J. Complement Med. Alt. Healthcare J., 2018; 8(1): 1-11. doi: 10.19080/JCMAH.2018.08.555727.

[6] Al-Bedah AMN, Elsubai IS, Qureshi NA, Aboushanab TS, Ali GIM, et al. The medical perspective of cupping therapy: Effects and mechanisms of action. J. Tradit. Complement Med., 2019; 9(2): 90-97. doi: 10.1016/j.jtcme.2018.03.003.

[7] Cheung BMY, Li C. Diabetes and hypertension: Is there a common metabolic pathway? Curr. Atherosclerosis Rep., 2012; 14: 160-66. doi: 10.1007/s11883-012-0227-2.
[8] Lloyd C, Smith J, Weinger K. Stress and Diabetes: A review of the links. Diabetes Spectr., 2005; 18: 121-27.

[9] LeBlanc ES, Kapphahn K, Stefanick M. Reproductive history and risk of type 2 Diabetes mellitus in postmenopausal women: Findings from the Women's Health Initiative. Menopause, 2017; 4(1): 64-72. doi: 10.1097/GME.0000000000000714.

[10]Coppell KJ, Kataoka M, Williams SM, Chisholm AW, Vorgers SM, et al. Nutritional intervention in patients with type 2 Diabetes who are hyperglycaemic despite optimised drug treatment-Lifestyle Over and Above Drugs in Diabetes (LOADD) study: Randomised controlled trial. BMJ, 2010; 341:c3337. doi: 10.1136/bmj.c3337. 